\title{
Metaheuristic approach proposal for the solution of the bi-objective course
}

\section{scheduling problem}

\author{
Esra Can ${ }^{\mathrm{a}, *}$, Ozden Ustun ${ }^{\mathrm{a}}$, Sahin Saglam ${ }^{\mathrm{b}}$ \\ ${ }^{a}$ Department of Industrial Engineering, Kutahya Dumlupinar University, Kutahya, Turkey; \\ ${ }^{b}$ Department of Informatics, Kutahya Dumlupinar University, Kutahya, Turkey.
}

Timetabling problems are among the commonly encountered problems in real life, from education institutions to airline companies. It is generally difficult to obtain optimal solutions for the timetabling problems that vary in terms of structures of constraints and objective functions, and these problems are considered being in NP-hard category, which cannot be solved in polynomial time in real life. In this study, a bi-objective mathematical model is proposed for a course scheduling problem in Kutahya Dumlupinar University Department of Industrial Engineering. While it is aimed in the first objective function to maximize the sum of the preferences of instructors determined by using the Analytic Hierarchy Process Method, it is aimed to minimize the students' course overlap in the other. Conic scalarization method is used to combine the objective functions. Due to NPhard nature of the problem, the Tabu Search Algorithm, one of metaheuristic approaches is used to solve it. Using the obtained data, the Tabu Search Algorithm by considering the proposed bi-objective mathematical model is designed for the problem and a software is developed in Excel Visual Basic program. The experimental results are evaluated with Analysis of Variance by using Minitab Program, comparing the results, satisfactory solutions are obtained.

Keywords: Multi-Objective optimization; conic scalarization; tabu search algorithm; experimental design; timetabling.

\section{Introduction}

Nowadays, despite the rapid development and advancement of management information technologies, many sectors still depend on manual execution instead of using computer software, which causes serious time losses. Eliminating the problems and losses occurring in the scheduling process and ensuring the flow without interruption are possible with optimizing the timetable according to the objectives of the system.

Timetabling is a decision-making process and is an approach that enables necessary allocations to resources within a certain time span and aims to use efficient time utilization. In general, creating a timetable is classified 
as the NP-hard problem and scheduling of staff, health, training are each examined as sub-headings of timetabling [1].

Course scheduling problems are in the class of timetabling problems and they are based on determining the hours to be assigned for the courses for each class by providing the required constraints [2]. When creating the course schedule, it is a priority rule to determine the hours of all the courses of the institution to be organized and that the prepared course schedule meets the defined needs and constraints [3]. These constraints are often defined as "compulsory (hard)" and "flexible (soft)". Hard constraints have to be satisfied under any conditions, whereas soft constraints need to be satisfied as much as possible and are not critical [4]. Various methods such as mathematical modelling, heuristic approaches, local search, evolutionary algorithms, and constraint-based approaches are used for course scheduling problems. In order to solve the university-timetabling problem, Ozturk et al. [5], developing a multi-objective decision-making model and presenting an approach considering class capacities and the preferences of instructors for course hours, solved the problem by the weighted-sum scalarization method. Badri [6] developed a two-stage optimization procedure in his multi-objective 0-1 integerprogramming model. In the first stage, he assigned the students to the courses by maximizing the course instructors' preferences through weighting. In the second stage, he tried to maximize the allocation of courseclassroom combinations to available time blocks. Ozdemir and Gasimov [7], proposing a three-stage process consisting of the Analytic Hierarchy Process (AHP), the Conic Scalarization and the Modified Gradient Method, used this integrated method for the first time to solve a non-convex multi-objective faculty course assignment problem. They computed the preferences and desires of instructors and administrators were in line with the priorities calculated by the AHP, and the objective functions were combined with the conic scalarization method. Aladag et al. [8], using the Tabu Search Algorithm, proposing two different neighborhood structures in addition to simple and swap movements, solved the problem using four neighborhood structures and compared the results statistically. Akkan and Gulcu [9] handled the course timetabling problem as a bi-criteria optimization problem and solve it by a hybrid multi-objective genetic algorithm, which makes use of hill climbing and simulated annealing algorithms besides to the standard genetic algorithm approach. Jamili et al. [10], presented a multiobjective and comprehensive mathematical model in their study. The first objective function try to design a timetable for the instructors have more time to do research works. The second objective function maximize the sum of instructors' day and hour preferences. Al-Yakoob and Sherali [11] proposed mathematical programming models, Al Hadid et al. [12] aimed at reaching a solution by using a simulated annealing algorithm, and AlJarrah et al. [13] performed a timetabling system by utilizing genetic algorithms. In their study involving 
solution methods for timetabling problems, Altunay and Eren [14] classified the relevant studies in the literature through various approaches.

In this study, an integrated approach consist of AHP, Tabu Search Algorithm and Conic Scalarization is proposed for the problem of preparing a timetable which is a common difficult problem usually encountered in educational institutions. A mathematical model is proposed for the problem of preparing the timetable of the Department of Industrial Engineering undergraduate program in Kutahya Dumlupinar University and the Tabu Search Algorithm, one of the metaheuristic approaches, is utilized for this purpose. While in the first objective function of the bi-objective model formed within the constraints defined in the problem, a questionnaire is developed to determine the preferences of the instructors and analysing the results using AHP. The sum of day and hour priorities of the instructors are tried to be maximized, in the second objective function, the total number of students whose courses overlapped is taken from the Student Information System (SIS) and tried to be minimized. The preference priorities obtained by AHP are used in the structure of the objective function. The biobjective function is turned into a single-objective function by using the Conic Scalarization. In this study, the Tabu Search Algorithm is adapted to the problem and the best solution is sought. Since an experimental design is needed to determine the factors and levels in the problem, a suitable experimental design is created for the designed model and the results of the experiments are compared and evaluated statistically by using the Analysis of Variance (ANOVA).

The course scheduling problem is tackled as a multiobjective problem and combined the objective functions by using the conic scalarization approach in this paper. In the first objective function, maximize the sum of the preferences of instructors, and it is aimed to minimize the students' course overlap in the second one. When reviewing the specialised literature, it is noted that the number of applications of the multiobjective metaheuristics to the class of course scheduling problems is scarce. In addition to this, has not been coincided a study that maximizes instructor preference and at the same time minimizes course overlap in multiobjective course scheduling problems in the literature. Furthermore, the use of a Tabu Search Algorithm also was not encountered in solving multiobjective course scheduling problems. This paper will offer a different perspective for researchers in this way. 


\section{Structure of the course scheduling problem and the mathematical model proposed for}

solution

The course schedule of Kutahya Dumlupinar University, Faculty of Engineering in the Department of Industrial Engineering is 5 days a week, 10 hours per day, between 08:00 am and 17:00 pm., totalling 50 hours a week. The program includes 62 courses, 34 instructors and 9 classrooms (6 classrooms, 1 laboratory, 2 amphitheatres) to be scheduled. Some instructors give more than one course. The timetable of the department includes the $1^{\text {st }}$ year, $2^{\text {nd }}$ year, $3^{\text {rd }}$ year and $4^{\text {th }}$-year courses for spring semester.

In the department, the timetable is done manually by the research assistants assigned at the beginning of each semester. Based on the 2016-2017 Spring Semester course schedule of the department, physical facilities, the limitations of the academic staff and the teaching process of the department are examined and the following information is obtained:

- It is already known in which kind of physical environment (classroom or laboratory) the lessons will be taught.

- The estimated number of students to take the course is determined inferentially and physical environment with an appropriate class capacity is assigned for each course.

- Courses are grouped as Compulsory, Social Elective (Soc. Elect.), Technical Elective (Tech. Elect.), Engineering Project (Eng. Project) and Engineering Design (Eng. Design).

- The curriculum consists of 8 semesters. It is known which courses are given in each semester, and the courses that each student group is to take are determined in advance within the course plan.

- Research assistants in charge of preparing the course program get in touch with each instructor before the start of the semester to be informed about the lessons they will give and the time intervals of the courses.

- Fifty minutes of training - teaching is defined as a lesson hour.

- Courses can be conducted in more than one session depending on the course time and the number of the course sessions is determined by the department. 2-or 3-hour courses can be conducted in one session and 4-hour courses can be divided into two sessions as 2 hours in each session while 5-hour courses can be conducted in two sessions as 3 plus 2 hours. It is also possible to conduct some courses in 4 hours without any alteration.

- The number of sessions for each course and the duration of each session are known in advance. 
As a result, in order not to disrupt the instructional plan, it is observed that all compulsory courses which should be opened in the related semester (spring or fall) in the course plan is opened, that the sufficient number of elective courses are opened and that the course load of the instructors is completed as much as possible.

\subsection{Bi objective 0-1 integer mathematical model for course timetabling (IMMCT)}

Indices, decision variables, parameters and clusters

Indices

$I=\{i \mid i=1,2, \ldots, m\}:$ Set of courses,

$J=\{j \mid j=1,2, \ldots, n\}:$ Set of days,

$K=\{k \mid k=1,2, \ldots, r\}:$ Set of daily course hours,

$N=\{n \mid n=1,2, \ldots, t\}:$ Set of student groups,

$L=\{l \mid l=1,2, \ldots, u\}:$ Set of instructors,

$I^{\prime}=I^{\prime}=I, J^{\prime}=J, K^{\prime}=K$.

Decision variables

$x_{i j k}=1$, if course $i$ is assigned to $j^{\text {th }}$ day and $k^{\text {th }}$ course hours; 0, otherwise;

Parameters

$D_{i}$ : Weekly total course hours of the $i^{\text {th }}$ course,

$V_{i, i^{\prime}}$ : Number of students with overlapping course $i$ and course $i$,

$T_{i j}: j^{\text {th }}$ day preference priority of the instructor of the $i^{\text {th }}$ course,

$H_{i k}: k^{\text {th }}$ hour preference priority of the instructor of the $i^{\text {th }}$ course.

$K_{l j}$ : Course hours which the instructor $l$ does not want to teach in the $j^{\text {th }}$ day,

$W_{l j}$ : Fixed and constant course hours of instructor $l$ on the $j^{\text {th }}$ day,

Subsets used in the model

$I_{w}:$ Courses with fixed days and hours,

$I_{l}:$ Courses given by the instructor $l$,

$I_{Z}:$ Compulsory courses,

$I_{S}:$ Elective courses.

Constraints

a) Constraints of instructors 
The instructors may submit the days and times they do not want to or will not give lessons in advance. Although this constraint is generally considered as an optional soft constraint, it is regarded as a strict constraint in our study (Equation 1). Equation (2) shows the courses with fixed and constant days and hours. The course hours of the courses given by an instructor in a semester should not overlap (Equation 3). This constraint is a strict constraint for all instructors.

$$
\begin{aligned}
& x_{i j k}=0, \forall \mathrm{i} \in I_{l},(\mathrm{j}, \mathrm{k}) \in K_{l j} \\
& x_{i j k}=1, \forall \mathrm{i} \in I_{w},(\mathrm{j}, \mathrm{k}) \in W_{l j} \\
& \sum_{i \in I_{l}} x_{i j k} \leq 1, \forall(j, k)
\end{aligned}
$$

\section{b) Curriculum period course clusters}

In the curriculum plan, the compulsory and elective course hours of fall or spring courses of a class must not overlap. This constraint is among the strict constraints. Each course is given a number, and the compulsory and elective course clusters are expressed with these numbers given in Table 1.

The sets of the compulsory courses and elective courses are determined as follows:

$$
\begin{array}{ll}
I_{Z 1}=\{i \mid i=1,2,3,4,5,6,7\} & I_{S 1}=\{i \mid i=20,21,22\} \\
I_{Z 2}=\{i \mid i=8,9,10,11,12\} & I_{S 2}=\{i \mid i=23,24,25\} \\
I_{Z 3}=\{i \mid i=13,14,15,16,17\} & I_{S 3}=\{i \mid i=26,27,28,29\} \\
I_{Z 4}=\{i \mid i=18,19\} & I_{S 4}=\{i \mid i=30,31\} \\
I_{Z}=\left\{I_{Z 1} \cup I_{Z 2} \cup I_{Z 3} \cup I_{Z 4}\right\} & I_{S 5}=\{i \mid i=32,33,34,35,36\} \\
& I_{S 6}=\{i \mid i=37,38,39,40,41\} \\
& I_{S}=\left\{I_{S 2} \cup I_{S 3} \ldots \cup I_{S n}\right\}
\end{array}
$$

Of the compulsory course set, IZ1 denotes the first year spring semester compulsory courses, Iz2 denotes the second year spring semester compulsory courses, IZ3 denotes the third year spring semester compulsory courses and $\mathrm{I}_{\mathrm{Z} 4}$ denotes the fourth year spring semester compulsory courses. 
Of the elective course set, $\mathrm{I}_{\mathrm{S} 1}$ denotes the second year spring semester elective courses, $\mathrm{I}_{\mathrm{S} 2}$ denotes the third year spring semester elective courses, $\mathrm{I}_{\mathrm{S} 3}$ denotes the fourth year spring semester $1^{\text {st }}$ Group elective courses, IS4 denotes the fourth year spring semester $2^{\text {nd }}$ group elective courses, $I_{S 5}$ denotes the fourth year spring semester $3^{\text {rd }}$ Group elective courses, and $I_{S 6}$ denotes the fourth year spring semester $4^{\text {th }}$ Group elective courses. The fourthyear $3^{\text {rd }}$ and $4^{\text {th }}$ group elective courses $\left(I_{S 5}, I_{S 6}\right)$ in the curriculum are not included in the constraints since they are scheduled on Saturday.

\section{c) Non-overlapping constraints of courses}

Combination of the compulsory and elective course sets is equal to the whole set of courses $(Z \cup S=I)$. Equations (4), (5), (6), and (7) refer to the non-overlapping constraints of the $1^{\text {st }}, 2^{\text {nd }}, 3^{\text {rd }}$, and $4^{\text {th }}$ year courses in the curriculum, respectively.

$$
\begin{aligned}
& \sum_{i \in I_{Z 1}} x_{i j k} \leq 1, \forall(j, k) \\
& x_{i^{\prime} j k}+\sum_{i \in I_{Z 2}} x_{i j k} \leq 1, \forall(j, k), \forall i^{\prime} \in I_{S 1} \\
& x_{i^{\prime} j k}+\sum_{i \in I_{Z 3}} x_{i j k} \leq 1, \forall(j, k), \forall i^{\prime} \in I_{S 2} \\
& x_{i^{\prime} j k}+x_{i^{\prime \prime} j k}+\sum_{i \in I Z 4} x_{i j k} \leq 1, \forall(j, k), \forall i^{\prime} \in I_{S 3} \forall i^{\prime \prime} \in I_{S 4}
\end{aligned}
$$

\section{d) Course Constraints}

Equation (8) denotes that all the courses in the curriculum pre-determined by the department are assigned as many as the course hours. Under the assumption that there are 9 classrooms available for the department, Equation (9) denotes the constraint of not having over 9 courses in the same class hour. Equation (10) denotes the sequence constraint that ensures that there is no other course between the course blocks in order not to disturb the integrity of the course. Equation (11) denotes the constraint that guarantees to assign two-course hours consecutively. Equation (12) denotes the constraint showing that the decision variable consists of 0-1 integer variables. These constraints are among the strict constraints in the model.

$$
\begin{aligned}
& \sum_{j=1}^{n} \sum_{k=1}^{r} x_{i j k}=D_{i}, \forall i \\
& \sum_{i=1}^{m} x_{i j k} \leq 9 ; \forall(j, k)
\end{aligned}
$$




$$
\begin{aligned}
& x_{i j k}+x_{i j(k+1)}-x_{i j(k-1)} \leq 0, \forall(i, j, k) \\
& -x_{i j k}+x_{i j(k+1)}-x_{i j(k+2)} \leq 0, \forall(i, j, k) \\
& x_{i j k}: 0-1 \text { int eger, } \forall(i, j, k)
\end{aligned}
$$

\section{Objective Functions}

Equation (13) denotes the first objective function, which enables the maximization of the sum of instructor preferences, and Equation (14) denotes the second objective function, which enables the minimization of the sum of the overlapping number of students in the consecutive classes.

$$
\begin{aligned}
& \operatorname{Max} f_{1}(x)=\sum_{i=1}^{m} \sum_{j=1}^{n} \sum_{k=1}^{r}\left(T_{i j}+H_{i k}\right) x_{i j k} \\
& \operatorname{Min} f_{2}(x)=\sum_{i=1}^{m} \sum_{j=1}^{n} \sum_{k=1}^{r} \sum_{i^{\prime}=1}^{m} \sum_{j^{\prime}=1}^{n} \sum_{k^{\prime}=1}^{r} V_{i i^{\prime}} x_{i j k} x_{i^{\prime} j^{\prime} k^{\prime}}
\end{aligned}
$$

AHP method is used to determine the course day and class hour preferences of the instructors in the problem. A questionnaire is given to the instructors to make the paired comparison of the determined criteria based on the Saaty [15] 1-9 scale and the consistency ratios are analysed. In order to minimize the total number of overlapping students in consecutive classes, the overlap numbers are determined from the SIS database and an overlap matrix is created.

Detailed solution steps of the proposed integrated approach using AHP, Tabu Search and Conic Scalarization Methods are shown in Figure 1.

\section{Determining the stochastic representation of the course timetabling by considering the (IMMCT) constraints}

Taking into account the IMMCT constraints, the stochastic representation of the course timetable is determined. The course list is created by enumerating each course. As the courses conducted in two sessions are considered as two separate groups, different numbers are given and listed. The first three-hour session of the Mathematics II course ranked at number 1 , while the two-hour session is ranked at number 3 . Table 2 is created by assigning numbers to courses respectively starting from the first-class courses.

The number of random numbers generated is equal to the number of courses, and the first course in the list is assigned to the number with the smallest random number. This process is repeated for all courses in the list, 
creating a random course order. By arranging the assigned random numbers from small to large, the new sequence of the courses according to random numbers is obtained as shown in Table 3.

In the course program, 37 one-hour gaps are assigned to have gaps between courses. If these empty hours are not defined, the program would assign the courses continuously and the lessons would stack in the first days of the week and the last days would be empty, leading to an incoherent timetable. The gaps are assigned to each class respectively as one hour. During the course assignment process, the overlap of the courses at distinct classes at the same time for the instructors with more than one course is prevented.

The courses listed according to the random numbers are placed in the classes in order of their numbers in Table 4. "Mathematics II" is placed to 08:00, 09:00 and 10:00 hours on Monday because the course's number is ranked at number 1. Because "History of Ataturk's Principles and Reforms II" is a second-year course, it is assigned to 08:00 and 09:00 hours on Monday. The course assignments are carried out respectively, and each class is assigned an empty course for one hour when the course number 29 "vacant hour" is reached. Also, when assigning the courses with course hours more than 3 conducted in two separate sessions to the program, positioning is done by considering the course with more course hours before. For example, since 5-hour Mathematics II is divided into two sessions as 3 and 2 hours, and the 3-hour session of this course is assigned before.

\section{Combining and computing objective functions with the conic scalarization method}

First of all, an overlap matrix is created by comparing the lists of students who have enrolled in the courses of the successive classes and have courses of the previous spring semester. The preferences of instructors are computed with the AHP method [16]. In the schedule, starting from the second year, first class and third class courses are checked for overlap. The overlapping courses of the successive classes are determined and the optimum position is sought in which they would not overlap with the previous and next class courses in the current column and would best suit the instructor preferences. If not found, secondly, the optimum position is sought that wouldn't overlap with at least one course in the previous and next class and would best meet the instructor preferences. If no suitable place could be found at this stage, placing the course in the best possible position with overlap check and taking the instructors' preferences into consideration, the appointment is carried out. After the position change of each course, the objective function is recomputed and a new value is obtained. By checking the overlapping in the neighborhood of the courses, the courses are assigned to the most appropriate places and the objective function is recomputed, yielding the best assignment. A single objective function is obtained by combining two objective functions through Conic Scalarization. The conic scalarization method 
allows the finding of all the efficient solutions corresponding to the decision maker's preferences in multiobjective optimization problems without convexity and boundedness assumptions [17]. Weights $w_{l}$ and $w_{2}$ in the formula are determined by AHP and taken as 0.5. Using Equation (15), the objective function is scalarized.

$\operatorname{Min} K S(x)=\alpha \sum_{k=1}^{2}\left|f_{k}(x)-R_{k}\right|+\sum_{k=1}^{2} w_{k}\left(f_{k}(x)-R_{k}\right)$

Subject to (1) - (14).

$(\alpha, w) \in\left\{0 \leq \alpha<w_{k}, k=1,2\right\}$ condition must be provided. Parameter values are $\alpha=\operatorname{Enk}\left\{w_{1}, w_{2}\right\}-0,01=0,49, R_{1}=$ $100, R_{2}=-35$ and $w_{1}=w_{2}=0,5$ so Conic Scalarization Objective Function becomes

$$
K S(x)=0,49 *\left(\left|f_{1}(x)-100\right|+\left|\left(-f_{2}(x)+35\right)\right|\right)+0,5 *\left(f_{1}(x)-100\right)+0,5 *\left(-f_{2}(x)+35\right)
$$

\section{Optimization with the tabu search algorithm}

The general steps of the algorithm for the problem-solving are as follows.

Step 1. A random start-up solution is created.

Step 2. The current solution is saved.

Step 3. Simple Move: A random course is selected and moved to a suitable space in its own column (from the same class).

Step 4. If there is no proper space, the course moving operation is cancelled.

Step 5. Randomly, two courses are chosen from the same column (from the same class).

Step 6. Equality of the number of courses' hours is checked.

Step 7. Swap Move: If the course hours are equal, the location of each course hour of the selected courses is swapped.

Step 8. If the course exchange is possible and the objective function improves, these courses are recorded in the tabu list.

Step 9. If the course hours are different from one another and there is no free time slot before and after for the course hours with more hours, there will be no change of courses

Step 10. If the iteration number has not exceeded the maximum value requested, return to the Step 3 .

Step 11. After all the procedures are applied, all placement possibilities are checked for all courses of all classes in the curriculum, when the course placement operation is performed and the maximum iteration is reached, the process is stopped. 


\section{1. Selection of parameters used in the tabu search algorithm}

The success of optimization processes with the Tabu Search Algorithm depends on the correct determination of the used-parameters given below.

\section{a) Selection of movement}

A movement selection mechanism is created when the algorithm is applied to the problem. Two types of movements are used for the course selection and taking courses to the tabu list. The first of these movements is the swap move. A random class is selected from a randomly generated course program. Two courses are selected randomly from the selected classes. The equality of the number of course hours for selected courses is checked. If the course hours are not equal, it would be checked whether there is sufficient vacant time before and after the courses to be replaced considering the course hours of the course that would replace. If the calculated value is better than the objective function value of the random solution created at the beginning, the two courses selected at this stage would be kept constant after the swap and these courses would be taken into the tabu list (Figure 2).

The study is repeated with a small sample to see the effect of swap move on the program. Industrial Engineering fourth year courses are chosen Monday through Friday to see the effects of swap move. Using only the swap move procedure, the program is run using the normal program for each tabu length and number of iterations. The results obtained are graphed by evaluating the first case and the situation after the experiments. In this way, the effect of swap move procedure to the conic objective function is seen. The tabu length has four levels $(4,6,8,12)$, iteration number has eight levels $(10,20,100,200,400,600,800,1000)$. While the tabu length is 4 and the iteration number is 10, these parameters are shown as "(4-10)" in the horizontal axis in Figure 3. This notation is repeated in all tabu length-iteration number combinations. Totally 32 combinations of the tabu length and the iteration number are created in this way.

Another movement type is the simple move based on the movement of courses into any space. In this movement type, all hours of the randomly-chosen course are randomly assigned to spaces equal to the number of hours per lesson (Figure 4).

\section{b) Selection of initial course schedule}

The experiments are carried out with three separate start-up programs. While a randomly initial appropriate solution is created, experiments are carried out with a single randomly generated program for all experimental groups as the first option, with a course schedule optimized with random search for all the experiments as the second option, and with randomly generated programs for each experiment as the last option and the results are recorded. 


\section{c) Use of candidate list strategy}

Because it will take a long time to examine all neighborhood structures to determine a specific solution, random class selection and random course selection are preferred to select the best one. A list of candidates with as many solutions as the number of courses is used.

\section{d) Selection of the movement rate}

Movement assignments are carried out by assigning values between [0-1] to swap move (swapping the courses) and simple move (moving to a vacant position). For example, while the swap move took 0,1 value, a simple move which moved the course into a random space, took 0.9 value and so the loop is completed. If the swap move is expressed as $\beta$ (beta) referring to $\beta=0,1 ; 0,2 ; 0,5 ; 0,8$ and 0,9 , then $1-\beta$ gives simple move.

\section{e) Tabu List Length Selection}

The courses are taken to the tabu list by entering the specified tabu lengths. Experiments are conducted with tabu lists with 4, 6, 8 and 12 lengths. Programs are run by the number of iteration, and when the tabu length is completed, the courses are removed with the first-in-first-out (FIFO) approach when the list reached the tabu length, thus entering among the courses that are actively swapped in the program.

\section{f) Tabu courses}

There are some courses in the tabu list at the solution starts. The courses that would not be changed in the program are included in this tabu list and these courses kept in memory are not subject to change even if there is overlap because these courses are under strict constraints with regard to day and hour in accordance with the preferences of instructors. These courses are "General Economics", "Numerical Analysis", "Management and Organization" and "Tech. Elect. Course IV". Assignment of the overlapping courses is done on the condition that the location of these courses did not change.

The interface screens of the software created in Excel Visual Basic according to the defined algorithm of the program are shown in Figure 5 and Figure 6. The "Program Assign" procedure is applied for the program run without using the Tabu Search Algorithm.

The "tabu list length" and "iteration number" counters under the "tabu search" screen are used for Tabu Search Algorithm. If the tests are to be performed by entering the move ratios, the "Movement with percentages" box is marked, and the "swap move" and "simple move" percentages under the "Movement Ratios" tab are entered in Figure 6 and the program is run. 


\section{Design of experiment for optimization of the conic objective function}

Design of experiment is an approach used to determine the effects of the independent variable considered to be the cause of change in the dependent variable for statistical analysis [18]. In order to evaluate the interactions of each of the factors in the tests performed with the data obtained from the experimental results, the experimental design tools of Minitab 17.0 application are studied full factorial. In the full factorial design, a combination is obtained by multiplying at least two or more factors and at least two or more levels of these factors [19].

In practice, total 4-factor and 20-level experiment is designed involving four levels $(4,6,8,12)$ for Tabu Length, eight levels for Iteration Number $(10,20,100,200,400,600,800,1000)$, five levels for Experiment Formation Percentages (Beta) $(0,1-0,9 ; 0,9-0,1 ; 0,2-0,8 ; 0,8-0,2 ; 0,5-0,5)$, three levels for Start-up Solution Alternatives (normal program, good program, random program).

Two Experimental Application Procedures, without tabu and without tabu percentage, are determined except for the factors given in the experimental design. In the experimental procedure without tabu, for each start-up solution, the program is run 15 times and the results are recorded. For each start-up solution alternative in the procedure without tabu percentage, the program is run for the number of iteration without entering the test percentages.

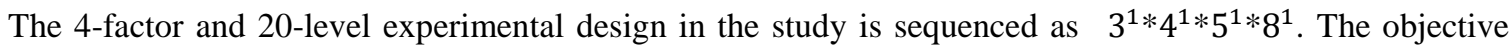
function is the dependent variable while tabu length, iteration number, program creation percentages, start-up solution alternatives are considered as independent variables. The tests are carried out for approximately two months and together with the tests in "without tabu" and "without tabu percentage" procedures, a total of 621 tests are performed. The increase in the tabu list length and the iteration number caused the experiments to be completed in a long time. However, it is determined that when the iteration number increased, the experimental time increased but good results are obtained.

The results obtained from the experimental study are statistically evaluated by Analysis of Variance (ANOVA).

\section{Analysis of variance}

ANOVA is used to compare the average of more than two populations with a normal distribution. The effects of independent variables on the dependent variable are investigated by ANOVA. The number of dependent and independent variables determines the type of ANOVA. "One-Way ANOVA" is used in Analysis of Variance with one dependent variable number. In the One-Way ANOVA, it is assumed that each group comes from the normal distribution and that the variances of the groups are relatively homogeneous [19]. 
A hypothesis test is put forth for statistical analysis. Because hypothesis tests are a comparison and selection process, more than one hypothesis is needed. These hypotheses are called alternative hypotheses. In this case, where $\mathrm{n}$ is the number of population and $\mu_{\mathrm{i}}$ is the average of test method $\mathrm{i}$, and $(i=1,2,3, \ldots, n)$, the initial hypothesis $\mathrm{H}_{0}$ and alternative hypothesis $\mathrm{H}_{1}$ are defined as follows:

$$
\begin{aligned}
& H_{0}: \mu_{i}=\mu_{j} \forall i, j, \quad i \neq j, \quad i, j=1,2,3, \ldots . ., n, \\
& H_{1}: \mu_{i} \neq \mu_{j}, \exists i, j, \quad i \neq j .
\end{aligned}
$$

A specific value is predicted for error margin in tests and expressed by alpha $(\alpha)$ usually being as small as 0.05 or 0.01 . Statistical programs calculate the error margin that occurs as a result of a hypothesis test and this value is called " $P$ " value. It is decided to accept or reject the hypothesis by comparing the $P$ value with the predetermined $\alpha$ value. If $P \leq \alpha, \mathrm{H}_{0}$ is rejected. If $P>\alpha, \mathrm{H}_{0}$ is accepted [20]. The significance level is taken as $\alpha=0.05$ in the study.

The results obtained from the experiments are subjected to ANOVA and pairwise comparison analysis of the variables is performed. The change values of four factors and objective function are evaluated. As a result of this analysis, it is observed that two factors displayed significant differences. These factors are determined as the "Iteration Number" and "Start-up Solution Alternatives" and are shown with the explanations of the ANOVA results (Figure 7 and Figure 8).

The test results of "Objective Function versus Iteration Number" showed a significant difference in seeing $\alpha=0,05$ significance level, $\mathrm{n}=8$ level, and $P=0,000<0,05$. Hypothesis $\mathrm{H}_{0}$ is rejected. The test results of "Objective Function versus Start-up Solution" showed a significant difference in seeing $\alpha=0,05$ significance level, $n=3$ level and $P=0,000<0,05 . \mathrm{H}_{0}$ hypothesis is rejected.

\section{Results}

While starting the solution process, the AHP method is applied to determine the preferences of instructors. Whole instructors fill the preferences form. The results are analysed using the AHP, then start to be made experiments to apply the Tabu Search Algorithm's parameters. The AHP and experiment processes take a long time, almost two months. The Tabu Search Algorithm has been designed by trying very different combinations (number of iterations, tabu length, etc.), thanks to the flexible structure of the software. In this way, the most suitable solution way has been determined. The statistical analysis is then started.

According to the results of the analysis, it is possible to determine between which averages the difference arose in the tests with a significant difference. "Iteration Number" and "Start-up Solution Alternatives" are 
determined as critical factors. In the determination of the variable effects on the objective function, the graphs in Figure 9 are used. The value of 800 iteration number is seen to have the minimum value in the Iteration Number graph. The "Good Program" variable has the minimum value in the Start-up Solution Alternatives in the graph.

As a result of the experiments, optimum objective function value is obtained as $(-1,504)$ by entering 6 tabu lengths, 400 iteration number, and selecting the initial solution as a good program without assigning the test percentages. As a result of this experiment, the course overlap is 20 and the instructor preference is 35,420 . In the convergence graph obtained, it is seen that the conic objective function value in the best objective value obtained from the experiment results converged to 400 iteration number (Figure 10). In the 2016-2017 Spring Semester Course Schedule prepared manually, course overlap is 696 , total instructor preference is 35,571 , and the scalarized objective function value is calculated as 589,334 . In this case, a significant improvement is seen in the curriculum when the current course schedule is compared with the results of the proposed approach's best solution obtained from the experiments in Table 5.

To determine the trade-off between the objective functions, the Tabu Search Algorithm is run 160 times for each of the initial solution as the normal program, the good program, and the random program. The best results are obtained by selecting the initial solution as the good program. The points obtained with the good program are shown in Figure 11. The Pareto points are marketed in dashed circles. There are four Pareto points among the obtained 160 points. It is shown that there is a trade-off between the points $(55 ; 36,782)$ and $(99 ; 38,638)$. While the student course overlap values change in the interval [55; 99], the instructor preferences values change in the interval $[36,782 ; 38,638]$ according to the Pareto points in Figure 11.

\section{Conclusion and future directions}

The course scheduling problem is a difficult optimization problem frequently encountered in the literature and tried to be solved by applying various methods. In this study, the problem is analyzed step by step and a metaheuristic an integrated approach is used for the solution. A bi-objective mathematical model is developed for the problem; two objective functions are designed to maximize the preferences of the instructor and to minimize student-course overlaps. Instructor preferences are taken by a designed questionnaire and are evaluated using the AHP method. Student-course overlaps are obtained from the Student Information System. The objective functions are transformed into a single objective function using the Conic Scalarization Method.

In order to solve the problem, the Tabu Search Algorithm, one of the heuristic approaches, is used and software is developed using Excel Visual Basic programming language. Experiments are conducted using different tabu lengths, iteration numbers and initial solutions, and the results are analyzed. It is seen in the test 
results that a significant improvement according to the conic objective function value and student-course overlaps is achieved by using the proposed approach. In addition, in the experiments, it is observed that the iteration number and start-up solutions revealed a significant difference in the minimization of the conic objective function.

It is thought to compare the proposed approach with different metaheuristic methods and scalarization approaches. A decision support system can be designed to obtain data from instructors by web application and the SIS database.

\section{References}

1. Lewis, R., Thompson, J. "Analysing the Effects of Solution Space Connectivity with an Effective Metaheuristic for the Course Timetabling Problem”, European Journal of Operational Research, 240, pp. 637$648(2015)$

2. Song, T., Liu, S., Tang, X., et al. “An Iterated Local Search Algorithm for the University Course Timetabling Problem", Applied Soft Computing, 68, pp. 597-608 (2018).

3. Yasari, P., Ranjbar, M., Jamili, N., et al. "A two-stage stochastic programming approach for a multi-objective course timetabling problem with courses cancelation risk", Computers \& Industrial Engineering, 130, pp. 650660 (2019).

4. Imran Hossain, S., Akhand, M. A. H., Shuvo, M. I. R., et al. "Optimization of University Course Scheduling Problem using Particle Swarm Optimization with Selective Search”, Expert Systems With Applications, 127, pp. 9-24 (2019).

5. Ozturk, Z.K., Kasimbeyli, N., Ozdemir, M.S., et al. "University Timetabling Problem Considering User Preferences", Journal of Industrial Engineering, 27(1), pp. 2-16 (2015).

6. Badri, M.A. "A Two-stage Multiobjective Scheduling Model for Faculty-Course-Time Assignments", European Journal of Operational Research, 94, pp. 16-28 (1996).

7. Ozdemir, M.S. and Gasimov, R.N. "The Analytic Hierarchy Process And Multiobjective 0-1 Faculty Course Assignment”, European Journal of Operational Research, 157, pp. 398-408 (2004). 
8. Aladag, C.H., Hocaoglu, G. and Basaran, M.A. "The Effect of Neighborhood Structures on Tabu Search Algorithm in Solving Course Timetabling Problem”, Expert Systems with Applications, 36(10), pp. 1234912356 (2009).

9. Akkan, C. and Gulcu, A. "A bi-criteria hybrid Genetic Algorithm with robustness objective for the course timetabling problem", Computers \& Operations Research, 90, pp. 22-32 (2018).

10. Jamili, A., Hamid, M., Gharoun, H., et al. "Developing a Comprehensive and Multi-Objective Mathematical Model for University Course Timetabling Problem: A Real Case Study", The 2nd European Int. Conf. on Industrial Engineering and Operations Management, Paris, France ( 2018).

11. Al-Yakoob, S.M. and Sherali, H.D. "A Column Generation Mathematical Programming Approach for a Class-Faculty Assignment Problem with Preferences”, Computational Management Science, 12, pp. 297-318 (2015).

12. AlHadid, I., Kaabneh, K., Tarawneh, H., et al. "Investigation of Simulated Annealing Components to Solve the University Course Timetabling Problem", Italian Journal of Pure and Applied Mathematics, 44, pp. 291$301(2020)$.

13. Al-Jarrah, M. A., Al-Sawalqah, A. A. and Al-Hamdan, S. F. "Developing a Course Timetable System for Academic Departments Using Genetic Algorithm", Jordanian Journal of Computers and Information Technology, 3(1), pp. 25-36 (2017).

14. Altunay, H. and Eren, T. "A Literature Review for Course Scheduling Problem”, Pamukkale University Journal of Engineering Sciences, 23(1), pp. 55-70 (2017).

15. Saaty, T.L. "How to Make a Decision: The Analytic Hierarchy Process", European Journal of Operational Research, 48(1), pp. 9-26 (1990).

16. Can, E. "Metaheuristic Approach Proposal for the Solution of the Multiobjective Course Scheduling Problem”, Master's Thesis. Institute of Science And Technology, Kutahya Dumlupinar University (2019). 
17. Ustun, O. "Interactive Reference Point Procedure Based on the Conic Scalarizing Function", The Scientific World Journal, 2014(5): 242803, (2014).

18. Montgomery, D.C. Design and Analysis of Experiments, 5th Edn., John Wiley Sons, New York, US (1991).

19. Kocacaliskan, I., Bingöl, N. A. Biyoistatistik [Biostatistics], 3th Edn., Nobel Academic Publications, Ankara, Turkey (2017).

20. Scheffe, H. The Analysis of Variance, 1st Edn., Wiley-Interscience, New York, US (1999).

Esra Can is currently $\mathrm{PhD}$ candidate at the Department of Industrial Engineering, Bursa Uludağ University, Bursa, Turkey. She is received MSc degree from the Industrial Engineering Department in Kutahya Dumlupinar University, Kutahya, Turkey. She received BSc degree from the Industrial Engineering from Yasar University, Izmir, Turkey. She received BSc degree from the Business Administration from Anadolu University, Eskisehir, Turkey. Her research interests include optimization, design of experiment, operation research, multi-criteria decision. She has academic studies published as article, book chapter.

Ozden Ustun is a Professor and head of department at the Industrial Enginnering Department in Kutahya Dumlupinar University, Turkey. He received his $\mathrm{PhD}$, MSc, BSc degree in Industrial Engineering at Eskisehir Osmangazi University, Eskisehir, Turkey. His research interests include operation research, multi-objectives modelling, production systems. He has published in journals such as the International Transactions In Operational Research, International Journal of Fuzzy System Applications, Journal of Industrial and Management Optimization, Omega - The International Journal of Management Science, Computers \& Industrial Engineering, Optimization, INFOR, Applied Mathematical Modelling among others.

Sahin Saglam is a Lecturer at the Informatics Department in Kutahya Dumlupinar University, Turkey. $\mathrm{He}$ is currently $\mathrm{PhD}$ candidate at the Department of Mathematics, 
Kutahya Dumlupinar University, Kutahya, Turkey. He received one of MSc degrees from the Mathematics, Anadolu University and the other one from Computer Engineering, Anadolu University. He received BSc degree from Mathematics, Anadolu University. His areas of research include database modeling, computer programming, database management, software engineering, object-oriented programming, operating systems, mathematics.

\section{Table Captions}

Table 1. Compulsory and elective courses in the curriculum.

Table 2. Numbering the sessions of the courses.

Table 3 . The new sequence obtained by sorting random course numbers from small to large.

Table 4. Developing a random course schedule.

Table 5. The objective function values.

\section{Figure Captions}

Figure 1. Flow chart of the proposed approach.

Figure 2. The swap move.

Figure 3. The swap move effects.

Figure 4. The simple move.

Figure 5. Course scheduling interface.

Figure 6. The interface of course scheduling rate move assigning.

Figure 7. ANOVA of objective function and iteration number.

Figure 8. ANOVA of objective function and start-up solution.

Figure 9. Effects of variables on the conic objective function.

Figure 10. The best conic objective function value according to the number of iteration value.

Figure 11. The Pareto curve obtained by the good program. 


\section{Tables}

Table 1.

\begin{tabular}{|c|c|c|c|}
\hline Compulsory Courses & $\begin{array}{c}\text { Course } \\
\text { No }\end{array}$ & Elective Courses & $\begin{array}{c}\text { Course } \\
\text { No }\end{array}$ \\
\hline Mathematics II (Mat. II) & 1 & Soc. Elect. Course II/ Entrepreneurship & 20 \\
\hline Physics II (Phys. II) & 2 & Soc. Elect. Course II/ Environmental Management Systems & 21 \\
\hline Technical Drawing (Tech. Draw.) & 3 & Soc. Elect. Course II/ Contemporary Approaches in Urban & \\
\hline General Economics (Gen. Eco.) & 4 & Construction & 22 \\
\hline Turkish Language II & 5 & Tech. Elect. Course II/ Object-Oriented Programming & 23 \\
\hline Computer Programming (Comp. Prog.) & 6 & Tech. Elect. Course II/ Service Systems & 24 \\
\hline English II (Eng. II) & 7 & Tech. Elect. Course II/ Business English II & 25 \\
\hline Statistics I & 8 & Tech. Elect. Course IV/ Database Management Systems & 26 \\
\hline Manufacturing Methods & 9 & Tech. Elect. Course IV/ Logistic Management & 27 \\
\hline Thermodynamics & 10 & Tech. Elect. Course IV/ Investment Project Analysis & 28 \\
\hline Numerical Analysis & 11 & Tech. Elect. Course IV/ Cellular Manufacturing Systems & 29 \\
\hline History of Ataturk's Principles and & & Tech. Elect. Course VI/ Scheduling Applications & 30 \\
\hline Reforms II (HAPR II) & 12 & Tech. Elect. Course VI/ Experimental Design & 31 \\
\hline Production Management & 13 & Eng. Project / Supply Chain Project & 32 \\
\hline Quality Control & 14 & Eng. Project / Modern Manufacturing Systems Project & 33 \\
\hline Operation Research II (Op. Res. II) & 15 & Eng. Project / Manufacturing Planning and Economy Project & 34 \\
\hline Engineering Economics (Eng. Eco.) & 16 & Eng. Project / Operational Research Project & 35 \\
\hline System Simulation (Syst. Sim.) & 17 & Eng. Project / Management Project & 36 \\
\hline Management and Organization & 18 & Eng. Design / Supply Chain Design & 37 \\
\hline \multirow[t]{4}{*}{ Ergonomics } & 19 & Eng. Design / Modern Manufacturing Systems Design & 38 \\
\hline & & Eng. Design / Manufacturing Planning and Economy Design & 39 \\
\hline & & Eng. Design / Operational Research Design & 40 \\
\hline & & Eng. Design / Management Design & 41 \\
\hline
\end{tabular}


Table 2.

\begin{tabular}{|c|c|c|c|c|c|}
\hline Course Name & $\begin{array}{l}\text { Course } \\
\text { Hours }\end{array}$ & $\begin{array}{c}\text { Course } \\
\text { Session No }\end{array}$ & Course Name & $\begin{array}{l}\text { Course } \\
\text { Hours }\end{array}$ & $\begin{array}{c}\text { Course } \\
\text { Session No }\end{array}$ \\
\hline Mathematics II & 3 & 1 & Social Elective Course II & 3 & 15 \\
\hline Physics II & 3 & 2 & Numerical Analysis & 3 & 16 \\
\hline Mathematics II & 2 & 3 & HAPR II & 2 & 17 \\
\hline Technical Drawing & 4 & 4 & Production Management & 3 & 18 \\
\hline Physics II & 2 & 5 & Quality Control & 4 & 19 \\
\hline General Economics & 3 & 6 & Operation Research II & 3 & 20 \\
\hline Turkish Language II & 2 & 7 & Engineering Economics & 3 & 21 \\
\hline Computer Programming Department. 1 & 3 & 8 & Technical Elective Course II & 3 & 22 \\
\hline Computer Programming Department. 2 & 3 & 9 & Operation Research II & 2 & 23 \\
\hline English II & 4 & 10 & System Simulation & 3 & 24 \\
\hline Statistics I & 2 & 11 & Technical Elective Course IV & 3 & 25 \\
\hline Manufacturing Methods & 4 & 12 & Management and Organization & 3 & 26 \\
\hline Thermodynamics & 3 & 13 & Technical Elective Course VI & 3 & 27 \\
\hline Statistics I & 2 & 14 & Ergonomics & 4 & 28 \\
\hline
\end{tabular}


Table 3.

\begin{tabular}{|c|c|c|c|c|c|c|c|c|c|}
\hline $\begin{array}{c}\text { Course } \\
\text { No } \\
\end{array}$ & $\begin{array}{c}\text { Random } \\
\text { No } \\
\end{array}$ & $\begin{array}{c}\text { Course } \\
\text { No } \\
\end{array}$ & $\begin{array}{c}\text { Random } \\
\text { No } \\
\end{array}$ & $\begin{array}{c}\text { Course } \\
\text { No } \\
\end{array}$ & $\begin{array}{c}\text { Random } \\
\text { No } \\
\end{array}$ & $\begin{array}{c}\text { Course } \\
\text { No } \\
\end{array}$ & $\begin{array}{c}\text { Random } \\
\text { No } \\
\end{array}$ & $\begin{array}{c}\text { Course } \\
\text { No } \\
\end{array}$ & $\begin{array}{c}\text { Random } \\
\text { No } \\
\end{array}$ \\
\hline 1 & 0,002 & 32 & 0,232 & 7 & 0,427 & 45 & 0,615 & 55 & 0,863 \\
\hline 19 & 0,047 & 4 & 0,284 & 40 & 0,44 & 46 & 0,641 & 56 & 0,879 \\
\hline 12 & 0,104 & 35 & 0,314 & 14 & 0,463 & 49 & 0,677 & 59 & 0,915 \\
\hline 18 & 0,105 & 36 & 0,326 & 13 & 0,464 & 16 & 0,694 & 60 & 0,919 \\
\hline 6 & 0,118 & 37 & 0,327 & 43 & 0,486 & 50 & 0,737 & 27 & 0,919 \\
\hline 5 & 0,184 & 38 & 0,369 & 44 & 0,521 & 28 & 0,788 & 63 & 0,95 \\
\hline 30 & 0,195 & 20 & 0,389 & 10 & 0,532 & 53 & 0,847 & 64 & 0,956 \\
\hline 31 & 0,197 & 39 & 0,411 & 24 & 0,575 & 54 & 0,858 & 65 & 0,989 \\
\hline
\end{tabular}


Table 4.

\begin{tabular}{|c|c|c|c|c|c|c|c|}
\hline COURSES & $\begin{array}{c}\text { COURSE } \\
\text { NO }\end{array}$ & DAY & HOURS & $\begin{array}{c}\text { CLASS } \\
\text { I } \\
\end{array}$ & $\begin{array}{c}\text { CLASS } \\
\text { II }\end{array}$ & $\begin{array}{c}\text { CLASS } \\
\text { III }\end{array}$ & $\begin{array}{c}\text { CLASS } \\
\text { IV } \\
\end{array}$ \\
\hline Mathematics II & 1 & \multirow{10}{*}{ 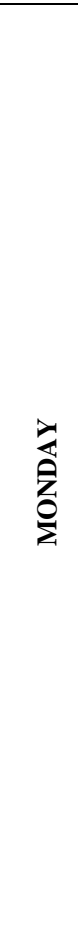 } & 08:00 & $\begin{array}{c}\text { Mathematics II } \\
1 \\
\end{array}$ & $\begin{array}{l}\text { HAPR II } \\
17\end{array}$ & $\begin{array}{l}\text { Quality Control } \\
19\end{array}$ & $\begin{array}{c}\text { Management and } \\
\text { Organization } \\
26 \\
\end{array}$ \\
\hline HAPR II & 17 & & 09:00 & $\begin{array}{c}\text { Mathematics II } \\
1\end{array}$ & $\begin{array}{l}\text { HAPR II } \\
17\end{array}$ & $\begin{array}{c}\text { Quality Control } \\
19\end{array}$ & $\begin{array}{c}\text { Management and } \\
\text { Organization } \\
26 \\
\end{array}$ \\
\hline Quality Control & 19 & & $10: 00$ & $\begin{array}{c}\text { Mathematics II } \\
1\end{array}$ & $\begin{array}{c}\text { Manufacturing } \\
\text { Methods } \\
12\end{array}$ & $\begin{array}{c}\text { Quality Control } \\
19\end{array}$ & $\begin{array}{c}\text { Management and } \\
\text { Organization } \\
26\end{array}$ \\
\hline $\begin{array}{l}\text { Management and } \\
\text { Organization }\end{array}$ & 26 & & $11: 00$ & $\begin{array}{c}\text { Physics II } \\
2 \\
\end{array}$ & $\begin{array}{c}\text { Manufacturing } \\
\text { Methods } \\
12 \\
\end{array}$ & $\begin{array}{l}\text { Quality Control } \\
19\end{array}$ & 29 \\
\hline Physics II & 2 & & $12: 00$ & $\begin{array}{c}\text { Physics II } \\
2 \\
\end{array}$ & $\begin{array}{c}\text { Manufacturing } \\
\text { Methods } \\
12 \\
\end{array}$ & $\begin{array}{c}\text { Production } \\
\text { Management } \\
18 \\
\end{array}$ & 30 \\
\hline $\begin{array}{l}\text { Manufacturing } \\
\text { Methods }\end{array}$ & 12 & & $13: 00$ & $\begin{array}{c}\text { Physics II } \\
2 \\
\end{array}$ & $\begin{array}{c}\text { Manufacturing } \\
\text { Methods } \\
12\end{array}$ & $\begin{array}{c}\text { Production } \\
\text { Management } \\
18\end{array}$ & 31 \\
\hline $\begin{array}{c}\text { Production } \\
\text { Management }\end{array}$ & 18 & & $14: 00$ & $\begin{array}{c}\text { General } \\
\text { Economics } \\
6\end{array}$ & 29 & $\begin{array}{c}\text { Production } \\
\text { Management } \\
18\end{array}$ & 32 \\
\hline General Economics & 6 & & $15: 00$ & $\begin{array}{c}\text { General } \\
\text { Economics } \\
6 \\
\end{array}$ & 30 & 29 & 33 \\
\hline Vacant & 29 & & $16: 00$ & $\begin{array}{c}\text { General } \\
\text { Economics } \\
6 \\
\end{array}$ & 31 & 30 & 34 \\
\hline Mathematics II & 3 & & $17: 00$ & 29 & 32 & 31 & 35 \\
\hline
\end{tabular}


Table 5.

\begin{tabular}{lccc}
\hline Program Type & \multicolumn{2}{c}{ Objective Functions } \\
\hline & $\begin{array}{c}\text { Student Course } \\
\text { Overlap }\end{array}$ & Preferences & $\begin{array}{c}\text { Conic Objective } \\
\text { Function }\end{array}$ \\
\hline Current Course Schedule & 696 & 35,571 & 589,334 \\
\hline Best Course Schedule & 20 & 35,420 & $-1,504$ \\
\hline
\end{tabular}




\section{Figures}

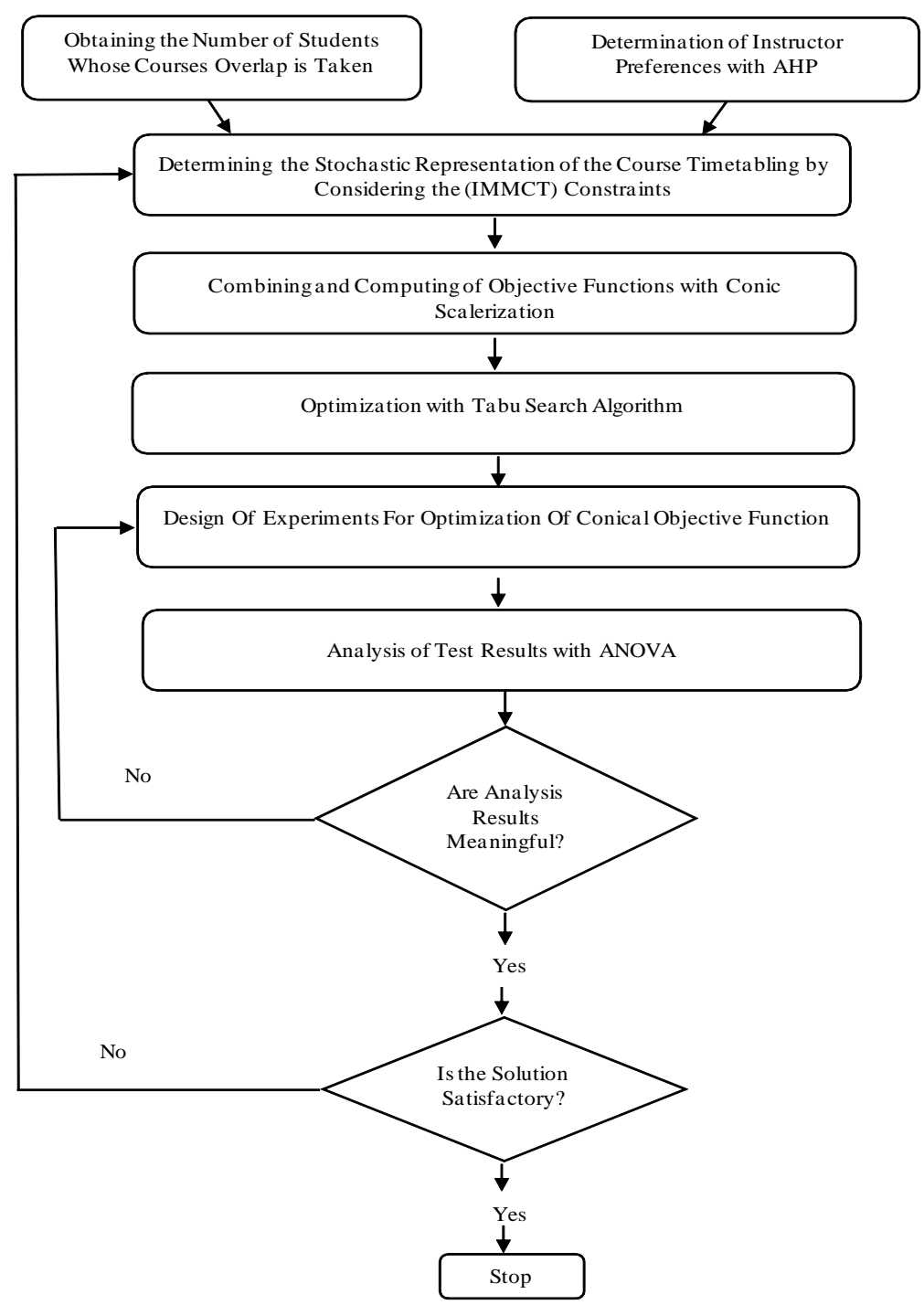

Figure 1. 


\begin{tabular}{|c|c|c|c|c|c|}
\hline DAY & HOUR & CLASS I & CLASS II & CLASS III & CLASS IV \\
\hline \multirow{10}{*}{ 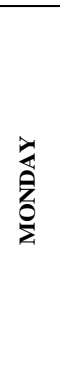 } & 8:00 & Mathematics II & H.A.P.R. II & Quality Control & Management and Organization \\
\hline & 9:00 & Mathematicy & H.A.P.R. II & ality Control & Management and Organization \\
\hline & 10:00 & Mathem/ics II & & Qually Control & Management and Organization \\
\hline & 11:00 & Phy fics II & & Quality ontrol & \\
\hline & $12: 00$ & Prfysics II & & Production Ma agement & \\
\hline & 13:00 & hysics II & & Production Man gement & \\
\hline & 14:00 & Genfral Economics & Manufacturing Methods & Production Mandgement & \\
\hline & 15:00 & Gen ral Economics & Manufacturing Methods & & \\
\hline & 16:00 & Gen ral Economics & Manufacturing Methods & & \\
\hline & 17:00 & & Manufacturing Methods & & \\
\hline \multirow{10}{*}{ 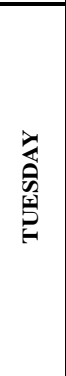 } & $8: 00$ & Ma hematics II & & & \\
\hline & 9:00 & Mat ematics II & Statistics I & & \\
\hline & 10:00 & Phy ics II & Statistics I & & \\
\hline & 11:00 & Physid II & & & \\
\hline & 12:00 & & & & \\
\hline & 13:00 & & & & \\
\hline & 14:00 & & & & \\
\hline & 15:00 & Computer Programming & Soc. Elect. Course II & Operation Research II & \\
\hline & 16:00 & Computer Programming & Soc. Elect. Course II & Operation Research II & \\
\hline & 17:00 & Computer Programming & Soc. Elect. Course II & Operation Research II & \\
\hline
\end{tabular}

Figure 2. 


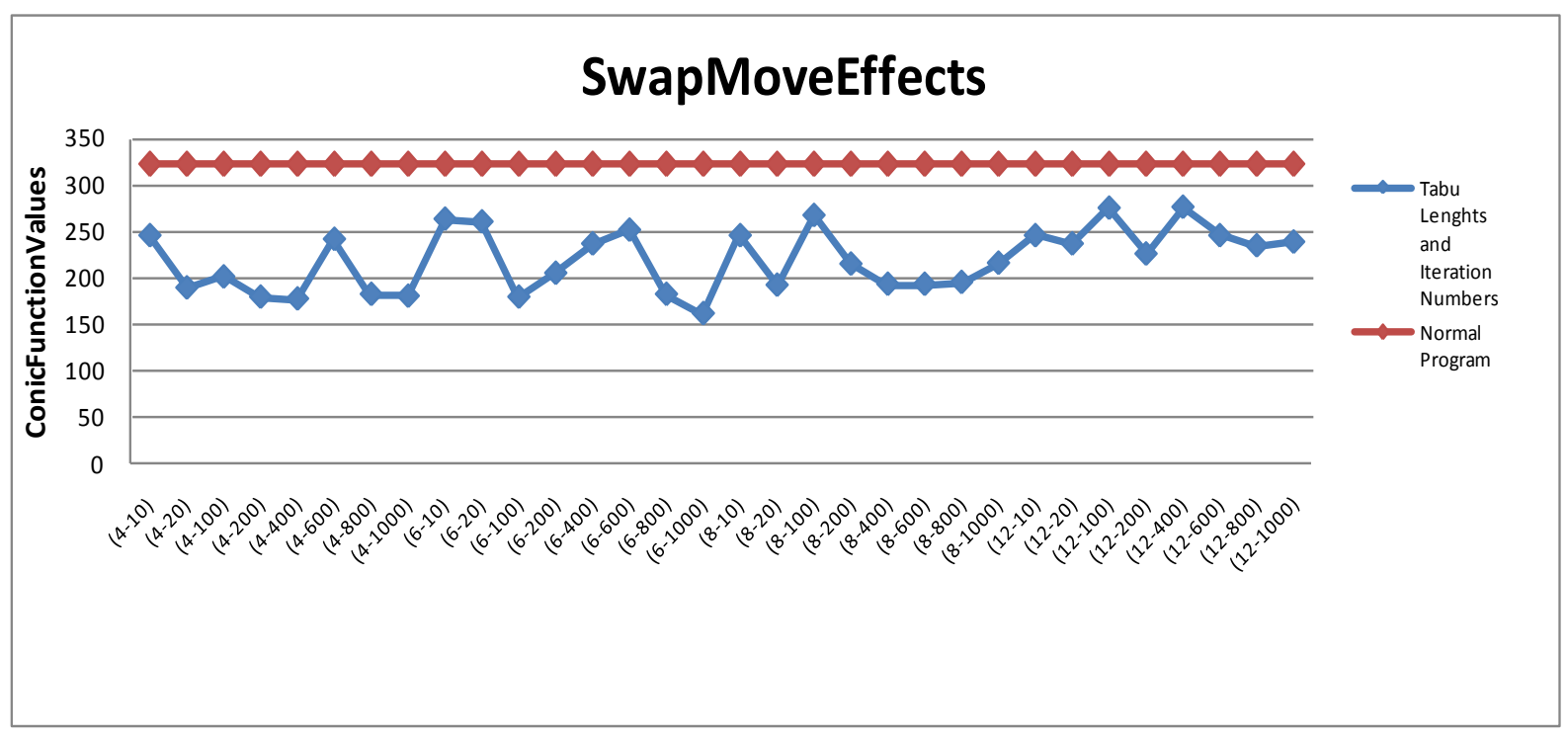

Figure 3. 


\begin{tabular}{|c|c|c|c|c|c|}
\hline DAY & HOUR & CLASS I & CLASS II & CLASS III & CLASS IV \\
\hline \multirow{10}{*}{ 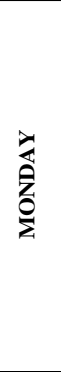 } & $8: 00$ & Mathematics II & H.A.P.R. II & Quality Control & Management and Organization \\
\hline & 9:00 & Mathematics II & H.A.P.R. II & Quality Control & Management and Organization \\
\hline & 10:00 & Mathematics II & & Qualit Control & Management and Organization \\
\hline & 11:00 & Physics II & & Quality ontrol & \\
\hline & 12:00 & Physics II & & Production Ma agement & \\
\hline & 13:00 & Physics II & & Production Man gement & \\
\hline & 14:00 & General Economics & Manufacturing Methods & Production Mandgement & \\
\hline & 15:00 & General Economics & Manufacturing Methods & & \\
\hline & 16:00 & General Economics & Manufacturing Methods & & \\
\hline & $17: 00$ & & Manufacturing Methods & & \\
\hline \multirow{10}{*}{ 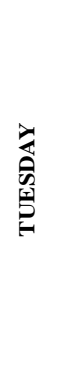 } & $8: 00$ & Mathematics II & & & \\
\hline & $9: 00$ & Mathematics II & Statistics I & & \\
\hline & 10:00 & Physics II & Statistics I & & \\
\hline & 11:00 & Physics II & & & \\
\hline & $12: 00$ & & & & \\
\hline & 13:00 & & & & \\
\hline & 14:00 & & & & \\
\hline & 15:00 & Computer Programming & Soc. Elect. Course II & Operation Research II & \\
\hline & 16:00 & Computer Programming & Soc. Elect. Course II & Operation Research II & \\
\hline & 17:00 & Computer Programming & Soc. Elect. Course II & Operation Research II & \\
\hline
\end{tabular}

Figure 4. 


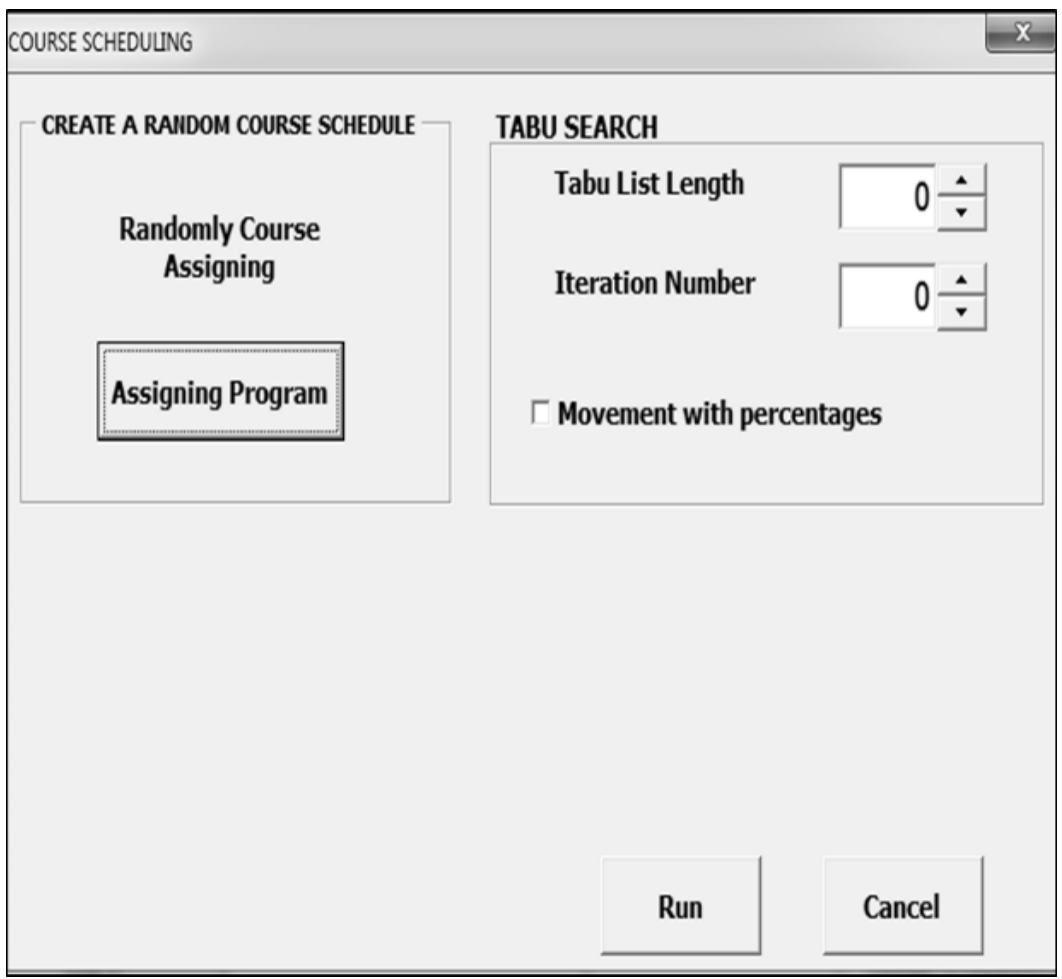

Figure 5.

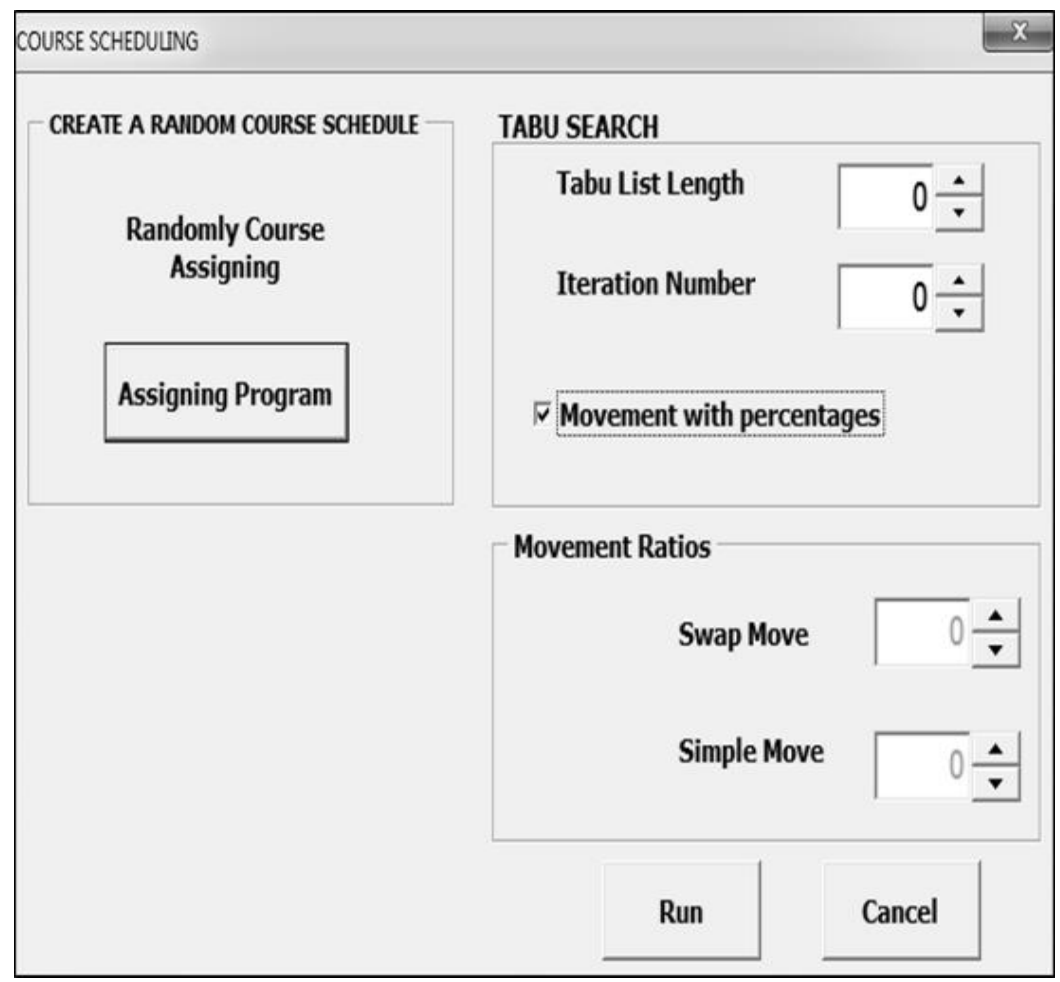

Figure 6. 


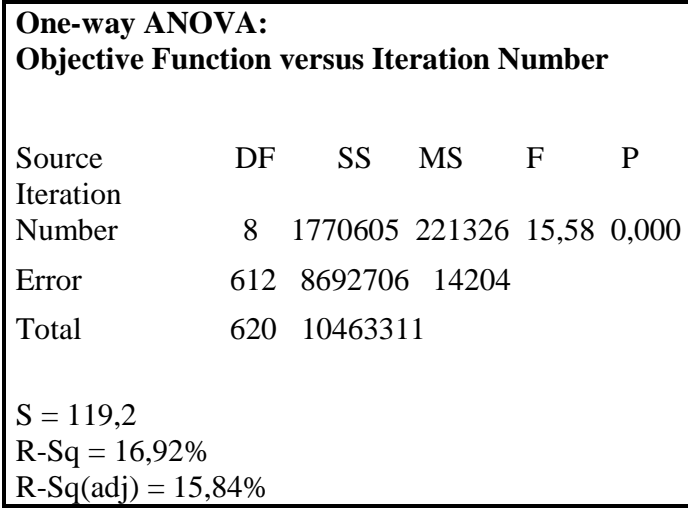

Figure 7.

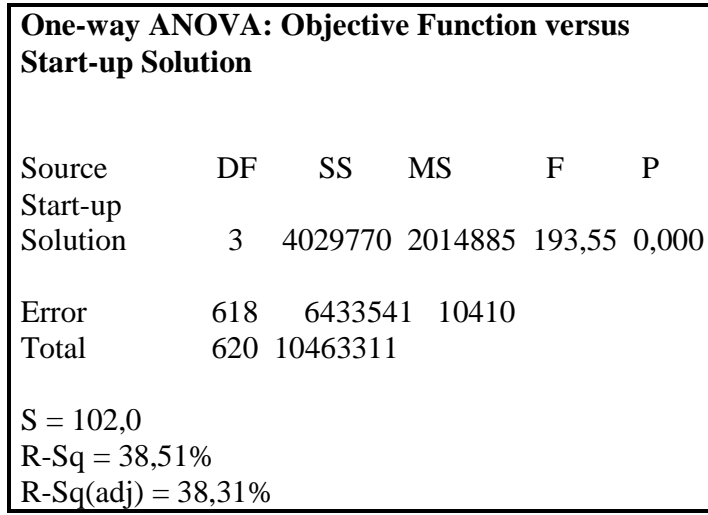

Figure 8. 


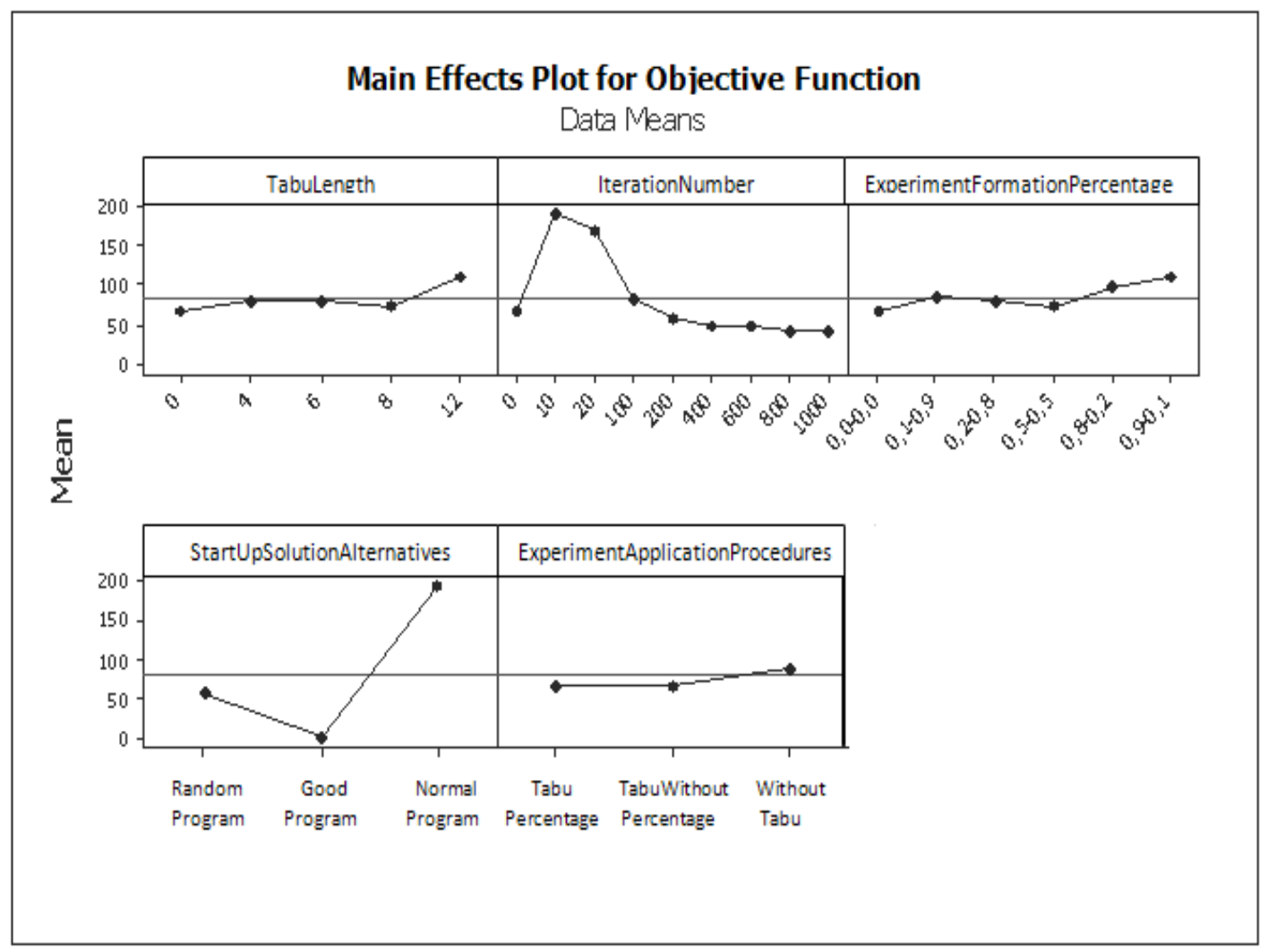

Figure 9. 


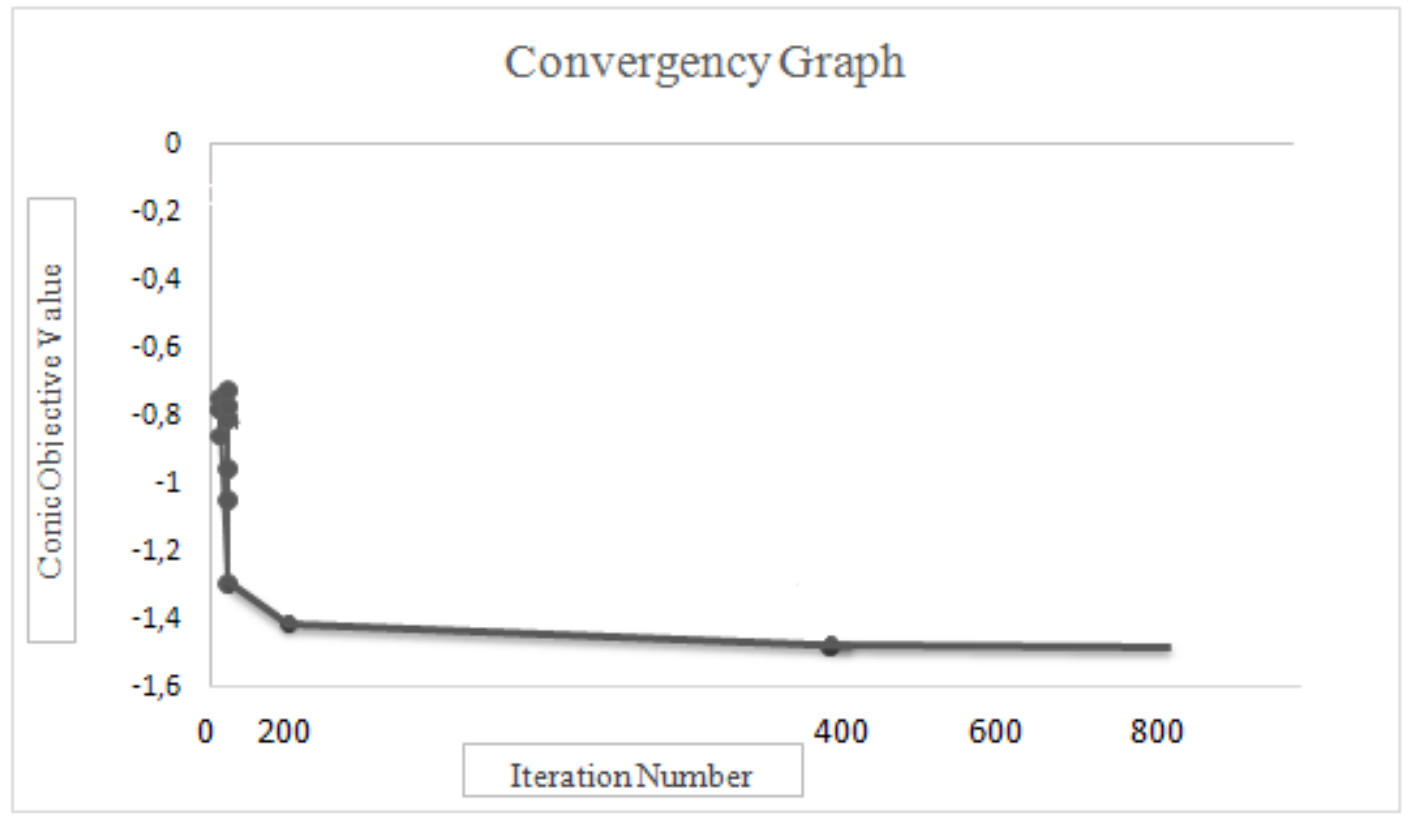

Figure 10. 


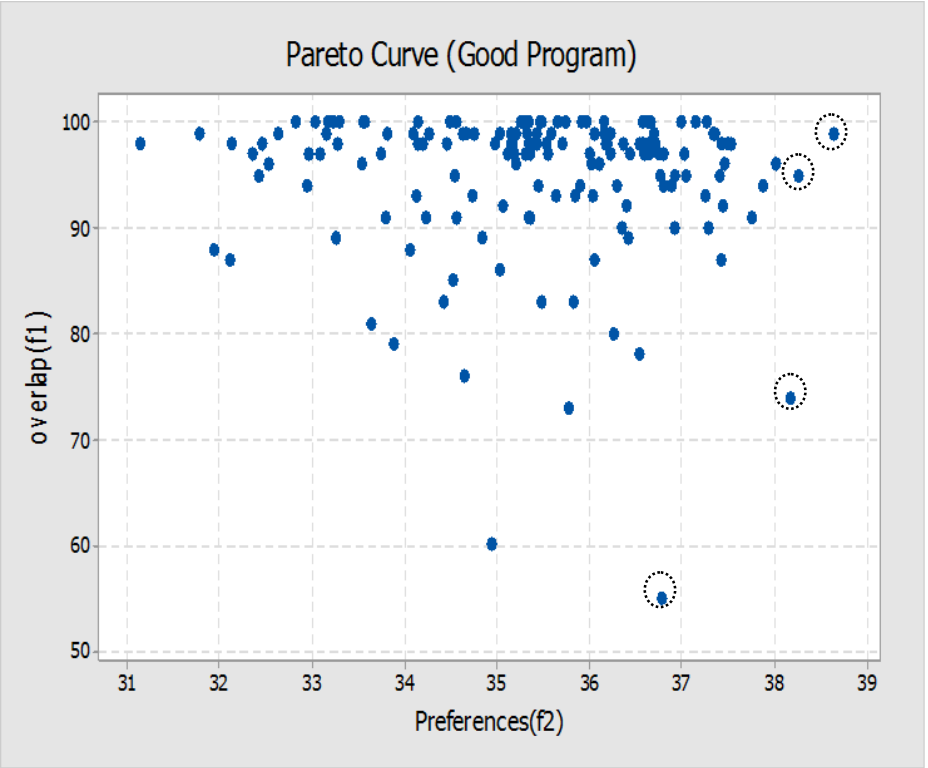

Figure 11. 